\title{
SUBMERGED ICE CRYSTALS IN GLACIERS
}

\section{By Alfred SchNeIder (Bern)}

WhILE wandering over the Lower Grindelwald Glacier in $1938 \mathrm{I}$ happened to find a peculiar formation of ice crystal which, I believe, has never been described. I wrote a short account of these crystals in Die Alpen.* I found them again several times afterwards so that it is not a question of a single occurrence.

In glacier tongues we often find crevasses or holes filled with water which does not freeze (see Fig. 4, p. 177). On the occasion in question I threw a stone into one of these holes and ice crystals of most unusual shapes and great beauty floated to the surface. I repeated this twenty or thirty times, and each time new crystals were dislodged from below. Naturally there was an appreciable interval before they reached the surface, as the holes are often very deep. The crystals were all flat-shaped and had the form of greatly magnified snowflakes (see Fig. 4). One surface was always quite flat; the other appeared to be carved or crenulated. Occasionally they had a kind of twinned structure in which two of the crenulated surfaces were in contact with the two flat surfaces pointing outwards.

In $193^{8}$ and $194^{2}$ I found these crystals without exception in very deep water-filled holes and came to the conclusion that depth played a part in their development, but my most recent investigations (1947) have made me alter this view. I also believed that the crystal masses grew in a horizontal direction. I was strengthened in this on learning that crystals growing in partly frozen water tanks developed in this manner.

My investigations were made easier in 1947 by the discovery of a hole which contained no water but showed remnants of these crystals. They were found at much smaller depths than before, namely $\mathrm{I}-3 \mathrm{~m}$., and I was therefore able for the first time to inspect them in their place of growth. In this case they grew nearly vertically downwards on projections in the narrow crevasse. I could not find any crystals growing horizontally.

In another crevasse, this time filled with water and inclined at an angle of $60^{\circ}$, I found the same conditions as in the dry hole, except that the crystals were much more abundant and more fully developed. They were growing downwards and were to be found at depths of only 1 or $2 \mathrm{~m}$. These crystals were always better formed than in the empty crevasses, in which they showed clear signs of melting. In addition to nearly structureless plates, I found many beautiful crenulated designs. The former were irregular and appeared to have developed at random, but the majority always seemed to branch at the customary angle of $60^{\circ}$, as is usual with most ice structures. The smallest was about the size of a child's hand, but I also found some as long as $3 \circ$ to $40 \mathrm{~cm}$.

At this stage it is far from clear whether we have here crystals which have really grown beneath the surface of the water, or whether they originated as crystals of the crevasse hoar type which had sublimed in empty crevasses and had subsequently become "drowned" by infiltrating melt water. In about a hundred water-filled crevasses which I have explored I have only found one or two cases of crystals which appeared to be of the latter type.

In many cases it is not easy to remove the crystals since their downward direction of growth renders it easy for stones to miss them. It is also not easy to dislodge them with long rods, as they usually lie so deep as to be quite out of sight, even in the clearest water; casual prodding seldom finds them.

\footnotetext{
- Vol. 17, 1939, p. 375-76.
} 
It is only possible at this stage to guess at the origin of these beautiful designs, but I hope in the near future to make further investigations which may throw more light on the problem.

(Whether the crystals observed by Dr. Schneider are a form of anchor ice or "drowned " sublimation crystals presents an interesting problem. A recent letter from Dr. Schneider describing further investigations made as soon as the glaciers became snow-free in 1948 casts doubt on the latter alternative, namely that the crystals formed by sublimation in winter and became submerged by spring thaw. It would be interesting to hear from anyene else who has
found these crystals in glacier holes. Ed.)

$M S$. received 24 November 1947

\section{STAGNANT GLACIER IN BRITISH COLUMBIA}

During Mr. F. S. Smythe's expedition in 1947 to the Lloyd George Mountains, British Columbia, the particularly interesting discovery was made of a large dying glacier. It lay in a deep canyonlike valley below the highest peaks of the group (see Fig. 3, p. 177). It was entirely blanketed in its own moraine and on its surface was a liberal growth of plants and small conifers, some of which reached $4.5 \mathrm{~m}$. in height. The glacier is $3.5 \mathrm{~km}$. long with a maximum width of some $400 \mathrm{~m}$. Its upper limit lies at about $1800 \mathrm{~m}$. and its snout at about $1350 \mathrm{~m}$.

Neither the small cliff-glacier at its snout, nor the avalanche snow from the precipitous rock walls enclosing it, appear to provide this glacier with any appreciable nourishment. The dead black ice could be seen in occasional exposures in sink-holes and at the glacier borders. The ice appeared to extend as far as the original terminal moraine. The melt water issuing from the latter was of moderate amount and scarcely turbid.

Since there was no clear evidence of recent glaciation beyond the terminal moraine, it seems probable that this glacier may be an example of re-establishment subsequent to the "climatic optimum," as has been claimed for others in the Cordilleran ranges.

As far as is known, this glacier is the only one in the Canadian Rockies proper in which the whole body of ice lies dead and stagnating beneath its mantle of moraine. It would seem to offer an example of what may well have occurred extensively at the close of the Glacial Epoch in regions of high relief possessing canyon-like or fjord valleys.

N. E. ODELL

\section{THE PRESERVATION OF ICE SPECIMENS IN REF R I GERA TOR S}

ON p. $21_{5}$ of this issue will be found an abstract from a paper by Dr. A. D. Howard describing the storage of samples of ice and their transference from the Antarctic to Washington. As one of the "European glaciologists" mentioned therein I would like to offer a word of caution. We certainly found that vaseline preserved ice specimens for the short time between collection and examination-usually a matter of a day or two. But M. de Quervain* has more recently made some experiments which show that under certain conditions the prevention of air contact is not sufficient. In the case of very delicate specimens such as snow flakes, immersion in paraffin oil at $-5^{\circ} \mathrm{C}$. did not prevent modifications in structure due to the surface migration of molecules. On the other hand at $-10^{\circ} \mathrm{C}$. no alteration could be detected even after some months.

G. Seligman

* Experientia (Basel), Bd. 1, Heft 7, 1945, p. 8. 


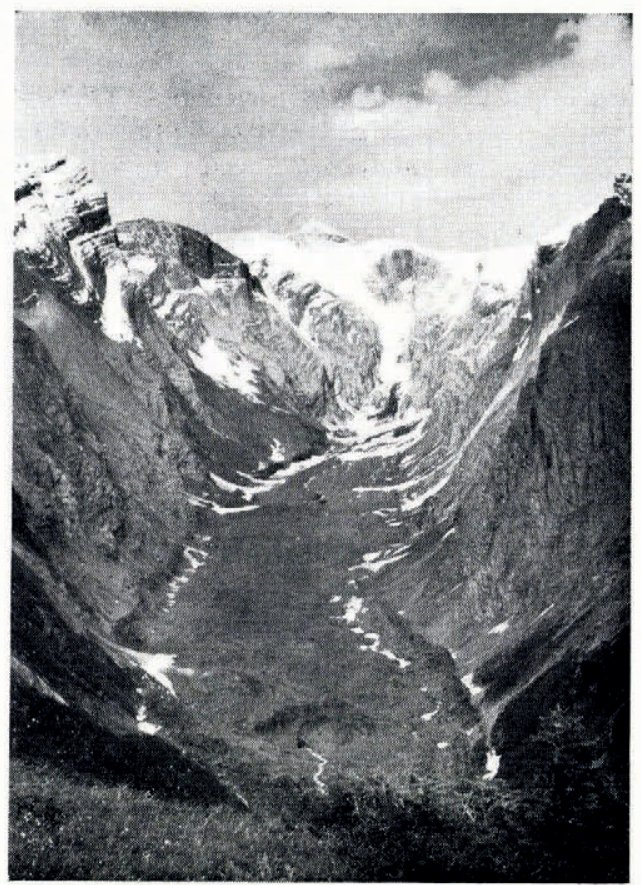

Fig. 3. Hidden Valley with Stagnant Glacier. Mt. David Lloyd George, the highest peak of the Lloyd George Mountains, in the background

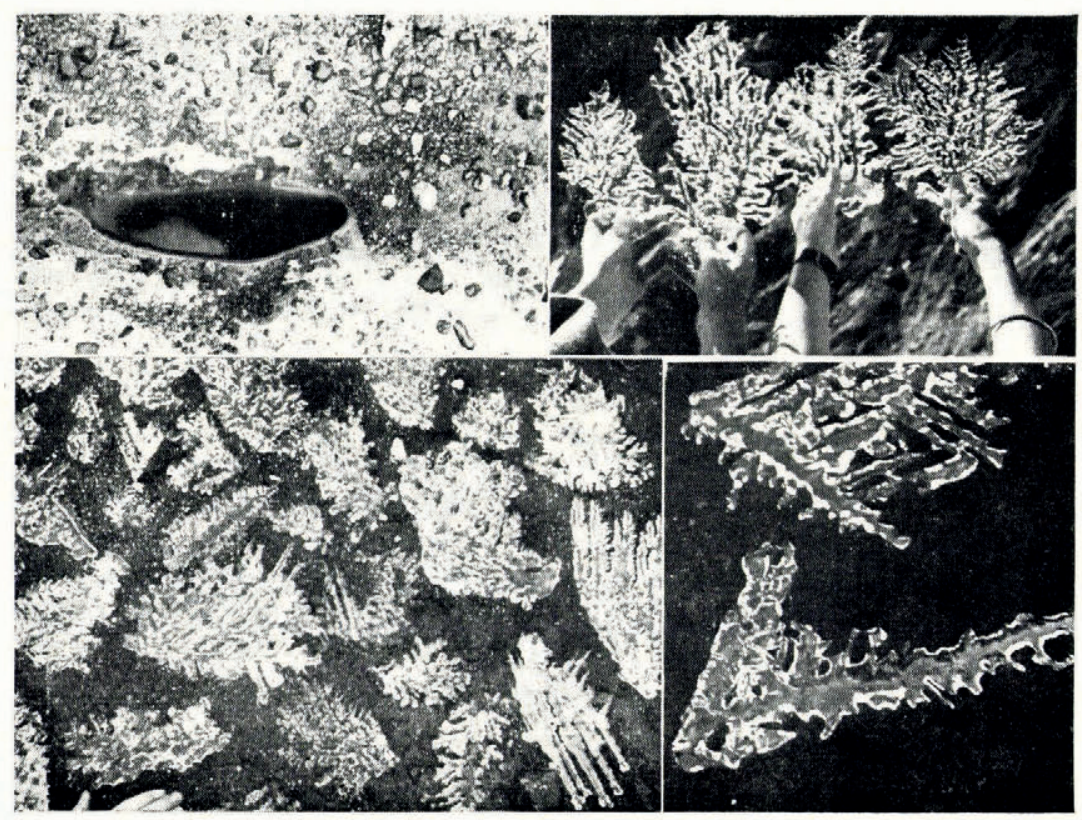

Fig. 4. Submerged Ice Crystals. Top left a small water-filled hole about $1 \mathrm{~m}$. across and several metres deep 